Article

\title{
Investigation on Stranski-Krastanow (SK) Growth Mode of Ag Coating in Cu/Ag Core-Shell Composites
}

\author{
Xingyuan Wan ${ }^{\circ}$, Yiyong Wang *, Jinlin Lu, Zhe Ning and Jidong Li \\ School of Materials \& Metallurgy, University of Science and Technology Liaoning, Anshan 114051, China; \\ wanxingyuan2017@163.com (X.W.); jinlinlu@hotmail.com (J.L.); classcl@126.com (Z.N.); \\ lijidong1014@163.com (J.L.) \\ * Correspondence: wangyiyongfly@163.com; Tel.: +86-412-5929559
}

Received: 20 February 2020; Accepted: 18 March 2020; Published: 23 March 2020

check for updates

\begin{abstract}
Cu} / \mathrm{Ag}$ core-shell composite was synthesized by the replacement-reduction method and was applied to the catalytic field. The specimens were analyzed by X-ray diffraction (XRD), scanning electron microscopy (SEM), and transmission electron microscope (TEM). The growth mechanism was investigated by the first-principles calculation, including the density of states, Mulliken population, and electronic structures. By comparing the calculation and characterization, it is concluded that the difference in interfacial properties leads to the growth of silver on the copper surface in the Stranski-Krastanow (SK) mode.
\end{abstract}

Keywords: density functional theory; composites; catalyst; growth mode

\section{Introduction}

Precious metals such as gold, platinum, and palladium are widely used in organic synthesis and the fuel cell [1-4]. The synthesis and surface modification of nano precious metal particles has become one of the hot topics in the catalytic field. However, precious metal materials are expensive to manufacture, especially nanoscale particles [5,6]. Furthermore, it is found that copper nanoparticles are used for catalytic synthesis. The copper nanoparticles are considered to be an ideal replacement for precious metal catalysts [7]. However, copper has obvious defects, that is, it is easily oxidized, resulting in a deactivation and seriously affecting catalytic efficiency. The price of silver is that of far from most precious metals and its properties are similar to precious metals. Therefore, the Ag coating on the surface of copper particles not only prevents the oxidation of copper but also preserves the catalytic efficiency [8].

It is well known that silver can be deposited by electroplating, but the electroplating on the surface of particles is difficult due to the low efficiency. Therefore, the displacement reaction was used to synthesize the core-shell composites owing to the different reduction potential between $\mathrm{Cu}$ and Ag. (The standard potential in aqueous solution at $25^{\circ} \mathrm{C}$ versus normal hydrogen electrode is $0.779 \mathrm{~V}$ for $\mathrm{Ag}$ and $0.340 \mathrm{~V}$ for $\mathrm{Cu}$ ). The reaction between $\mathrm{Cu}$ and $\mathrm{Ag}^{+}$is the key step in the synthesis. Therefore, complexing agents, such as ethylenediaminetetraacetic acid (EDTA), ammonium hydroxide $\left(\mathrm{NH}_{3} \cdot \mathrm{H}_{2} \mathrm{O}\right)$, sodium thiosulfate $\left(\mathrm{Na}_{2} \mathrm{~S}_{2} \mathrm{O}_{3}\right)$, are used to inhibit the rate [9]. However, $\mathrm{Cu}^{2+}$ produced by the reaction easily reacts with the complexing agent, and copper has a strong adsorption effect on the complex ions, preventing further copper replacement. Another method is to use a reducing agent to reduce $\mathrm{Ag}^{+}$from the plating solution and use copper atom nucleation centers to gradually grow silver particles on the surface of the copper powder to obtain a continuous coating. However, the stability of the plating solution is poor. Especially when a strong reducing agent is present, the plating solution is easily decomposed. In addition, the electroless plating reaction rate is fast, it is not easy to control, and related research work is lacking [10]. 
The morphology of particles is related to the catalytic properties, so the growth mode of the coating has attracted great attention. Heteroepitaxial growth has been demonstrated in film materials, which is dependent on the lattice mismatch between the coating and the substrate [11,12]. In core-shell composites, the HRTEM images of the interface were used to investigate the deposition of the coating. It is reported that the growth of $\mathrm{Ag}$ coating on $\mathrm{Cu}$ nanowires confirms to heteroepitaxial growth, and the Ag shell retains the same crystallographic orientation and twin structure as $\mathrm{Cu}$ nanowires [13]. However, for spherical particles, the growth mode of shell and the relationship between the substrate and the coating are not clear. First-principles calculations can simulate the growth of coatings, but there is no quasi-deterministic method for the calculation of core-shell models. Non-periodic or low-periodic core-shell models are used to explore the growth mechanism of the shell, but this is obviously different from reality, and the calculation results are not suitable for large-scale material systems [14].

In this study, we reported a new method for preparing $\mathrm{Cu} / \mathrm{Ag}$ core-shell particles and investigated the growth mechanism of Ag coatings by first-principles. By establishing a periodic model in the $x, y, z$ directions, the properties of the $\mathrm{Cu} / \mathrm{Ag}$ interface were analyzed, and the results were compared with the characterization results to verify the accuracy of the calculation. The $\mathrm{Cu} / \mathrm{Ag}$ core-shell synthesized by this method has potential for application in many fields, and provides a theoretical reference for the synthesis and design of core-shell composites.

\section{Materials and Methods}

\subsection{Synthesis of Copper Particles}

All chemicals in the experiments were of analytical grade and were used without further purification. In the synthesis of copper particles, $500 \mathrm{~mL}$ aqueous solution was stirred at $120^{\circ} \mathrm{C}$ for $6 \mathrm{~h}$ in an autoclave (Anhui Kemi Machinery Technology Co., Ltd., Anhui, China) with a total volume of $1 \mathrm{~L}$. The concentrations of cupric oxide $(\mathrm{CuO})$, sodium hydroxide $(\mathrm{NaOH})$, and glucose $\left(\mathrm{C}_{6} \mathrm{H}_{12} \mathrm{O}_{6}\right)$ in the solution were 72,72 , and $189 \mathrm{~g} / \mathrm{L}$, respectively. After the autoclave was cooled to room temperature, the copper particles were collected by centrifugation at $5000 \mathrm{r} / \mathrm{min}$, washed 3 times with distilled water, and 5 times with ethanol, and were then vacuum dried at $70{ }^{\circ} \mathrm{C}$ for $10 \mathrm{~h}$.

\subsection{Synthesis of $\mathrm{Cu} / \mathrm{Ag}$ Core-Shell Composites}

Copper powder is easily oxidized during drying and storage, so pickling must be performed before the composites are synthesized. In total, $100 \mathrm{~mL}$ of $10 \%$ dilute sulfuric acid, $100 \mathrm{~mL}$ of absolute ethanol, and $4 \mathrm{~g}$ of copper particles were stirred in a water bath at $60^{\circ} \mathrm{C}$ for $30 \mathrm{~min}$. After pickling, copper particles were collected by centrifugation at $5000 \mathrm{r} / \mathrm{min}$ and washed 3 times with distilled water. Then, the wet copper particles were added to $200 \mathrm{~mL}$ of $5 \%$ dilute aqueous ammonia at $60^{\circ} \mathrm{C}$, and $2.5 \mathrm{~g}$ of glucose powder was further added to the mixed solution. Finally, a freshly prepared silver ammonia solution $\left(\mathrm{Ag}\left(\mathrm{NH}_{3}\right)_{2} \mathrm{OH}\right)$ was slowly dropped into the mixed solution using a peristaltic pump. In a typical silver ammonia solution synthesis, one would add 3 drops of $10 \%$ sodium hydroxide solution $(\mathrm{NaOH})$ to $100 \mathrm{~mL}$ of $4 \%$ silver nitrate solution $\left(\mathrm{AgNO}_{3}\right)$, and add $25 \%$ concentrated ammonia water $\left(\mathrm{NH}_{3} \cdot \mathrm{H}_{2} \mathrm{O}\right)$ until precipitation. Mechanical agitation and ultrasonic oscillation were maintained during the synthesis in order to eliminate the agglomeration of ultrafine particles.

\subsection{Characterization of Specimen}

The X-ray diffraction technique (X'Pert Powder, PANalytical, Almelo, The Netherlands) was used to analyze the phase composition ( $\mathrm{Cu} \mathrm{K} \alpha$ filtered radiation, step $=0.02^{\circ}$, scanning speed $=10^{\circ} / \mathrm{min}$, 2 theta ranged from $10^{\circ}$ to $\left.100^{\circ}\right)$. The morphological features were complemented by scanning electron microscopy (SEM) (1 KV 15 KV, Zeiss- $\Sigma$ IGMA HD, Carl Zeiss, Oberkochen, Germany) and transmission electron microscopy (TEM) (200 KV, JEM-2100F, JEOL, Tokyo, Japan). 


\subsection{Method of Calculation}

All calculations were performed by a first-principles method on density functional theory (DFT), as implemented in the Cambridge series total energy package (CASTEP) code. The generalized gradient approximations (GGA) of the Perdew-Burke-Ernzerhof (PBE) approach were implemented to describe the exchange-correlation functional. The cut-off energy of the plane-waves basis set used to represent the balance electron was $351.00 \mathrm{eV}$. The k-point sampling grids obtained by using the Monkhorst-Pack method were set to $8 \times 8 \times 8$ and $8 \times 8 \times 1$ for the bulk and all slabs. All atoms were relaxed to their equilibrium position, where the optimization period always changed to a final convergence of less than $5.0 \times 10^{-6} \mathrm{eV} /$ atom. The forces on all atoms were minimized to less than $0.01 \mathrm{eV} / \AA$, stress was clobbered to $0.01 \mathrm{GPa}$ on each atom, and the displacement was converted to $5 \times 10^{-4} \AA$ [15]. Using the Broyden-Fletcher-Goldfarb-Shannon (BFGS) algorithm to automatically relax the internal coordinates of the atom means that the system can always be minimized. The super-soft pseudo-potentials were utilized to describe the interaction between the ion nucleus and valence electrons. For the $\mathrm{Cu}$ and $\mathrm{Ag}$, the valence electrons considered in their pseudopotential were $\mathrm{Cu} 3 \mathrm{~d}^{10} 4 \mathrm{~s}^{1}$ and $\mathrm{Ag} 4 \mathrm{~d}^{10} 5 \mathrm{~s}^{1}$. The surfaces and interfaces were modeled by the supercell method with periodic boundary conditions, and the thickness of the vacuum layer was $15.0 \AA$.

\section{Results}

\subsection{Characterization of Specimens}

$\mathrm{Ag}$ has a higher reduction potential than $\mathrm{Cu}$, and $\mathrm{Ag}^{+}$ions are reduced into $\mathrm{Ag}$ atoms by transforming $\mathrm{Cu}$ atoms into $\mathrm{Cu}^{2+}$. However, $\mathrm{Ag}^{+}$ions are present in a glucose-rich alkaline solution. There is a direct reduction reaction of $\mathrm{Ag}^{+}$ions, which is called a "replacement-reduction" method. The chemical equations for silver ammonia solution and silver deposition are as follows $[16,17]$ :

$$
\begin{gathered}
\mathrm{Ag}^{+}+\mathrm{NH}_{3} \cdot \mathrm{H}_{2} \mathrm{O}=\mathrm{AgOH}+\mathrm{NH}_{4}^{+} \\
\mathrm{AgOH}+2 \mathrm{NH}_{3} \cdot \mathrm{H}_{2} \mathrm{O}=\left[\mathrm{Ag}\left(\mathrm{NH}_{3}\right)_{2}\right]^{+}+2 \mathrm{H}_{2} \mathrm{O} \\
\mathrm{Cu}+2\left[\mathrm{Ag}\left(\mathrm{NH}_{3}\right)_{2}\right]^{+}=\left[\mathrm{Cu}\left(\mathrm{NH}_{3}\right)_{4}\right]^{2+}+2 \mathrm{Ag} \\
2\left[\mathrm{Ag}\left(\mathrm{NH}_{3}\right)_{2}\right]^{+}+\mathrm{C}_{6} \mathrm{H}_{12} \mathrm{O}_{6}+\mathrm{OH}^{-}=2 \mathrm{Ag}+\mathrm{NH}_{4}^{+}+\mathrm{H}_{2} \mathrm{O}+\mathrm{NH}_{3}+\mathrm{C}_{6} \mathrm{H}_{11} \mathrm{O}_{7}^{-} \\
2 \mathrm{Cu}+8 \mathrm{NH}_{3} \cdot \mathrm{H}_{2} \mathrm{O}+\mathrm{O}_{2}=2\left[\mathrm{Cu}\left(\mathrm{NH}_{3}\right)_{4}\right]^{2+}+4 \mathrm{OH}^{-}+6 \mathrm{H}_{2} \mathrm{O}
\end{gathered}
$$

$\mathrm{Cu}$ and $\mathrm{Ag}$ are almost immiscible at room temperature, but $\mathrm{Cu}$ is the faster diffusion species in the $\mathrm{Cu} / \mathrm{Ag}$ diffusion couple. $\mathrm{Cu}$ atoms at the $\mathrm{Cu} / \mathrm{Ag}$ interface diffuse to the $\mathrm{Ag}$ surface and exchange with $\mathrm{Ag}^{+}$ions by leaving vacancies at the interface as a result of the Kirkendall effect. In this paper, the key to inhibit the Kirkendall effect is to add 5\% dilute ammonia to inhibit the displacement reaction. Since the $\left[\mathrm{Cu}\left(\mathrm{NH}_{3}\right)_{4}\right]^{2+}$ ion is generated, the Equation (3) is inhibited during the coating process.

$\mathrm{The} \mathrm{Cu} / \mathrm{Ag}$ core-shell composite replicate the spherical structure of the $\mathrm{Cu}$ particles (Figure $1 \mathrm{a}, \mathrm{b}$ ), while the particle size distribution of specimens show that the two materials have similar average particle sizes (227.17 $\mathrm{nm}$ for $\mathrm{Cu}, 234.96 \mathrm{~nm}$ for $\mathrm{Cu} / \mathrm{Ag}$ core-shell composite), but the size of $\mathrm{Cu} / \mathrm{Ag}$ core-shell composite is slightly larger than the $\mathrm{Cu}$ particles (Figure 1i). Considering the agglomeration properties of the nanoparticles, for each sample, a large number of SEM images were measured, then 2000 particles were randomly selected for measurement and statistics, and the particle size distribution map was finally drafted. This phenomenon proves once again that Equation (3) is effectively inhibited, and the reduction reaction of $\mathrm{Ag}^{+}$ions mainly occurs in the solution. X-ray diffraction (XRD) measurements were made on the specimens to assess the structure and phase purity. The diffraction peaks can be indexed to a Copper, syn structure of $\mathrm{Cu}$, Copper, syn, and Silver-3C, syn structure of $\mathrm{Cu} / \mathrm{Ag}$ core-shell composite, as shown in Figure 1c. No diffraction peaks from impurities were found in the specimens. These results provide parameters for the simulations below. However, 
the peaks of the $\mathrm{Cu} / \mathrm{Ag}$ core-shell composite are significantly broadened, demonstrating that the crystallinity of the material deteriorated. To ascertain the core-shell structure, the TEM and SEM-EDS cross-sectional images are presented in Figure 1g. In Figure 1e,f, the TEM image of the specimen confirms that it is indeed a core-shell structure, and the average thickness of the shell layer is about $40 \mathrm{~nm}$. The SAED and EDS patterns further confirm the core-shell structure and the components. In Figure 1g, there is a strong intensity of copper on the core and a weak intensity of silver on the shell, and the composites contain $21.86 \mathrm{wt} . \%$ of $\mathrm{Ag}, 78.14 \mathrm{wt} . \%$ of $\mathrm{Cu}$. (The background value of the epoxy resin has been removed). The above characterization results are similar to those in the literature, proving that the material synthesis is successful [13].
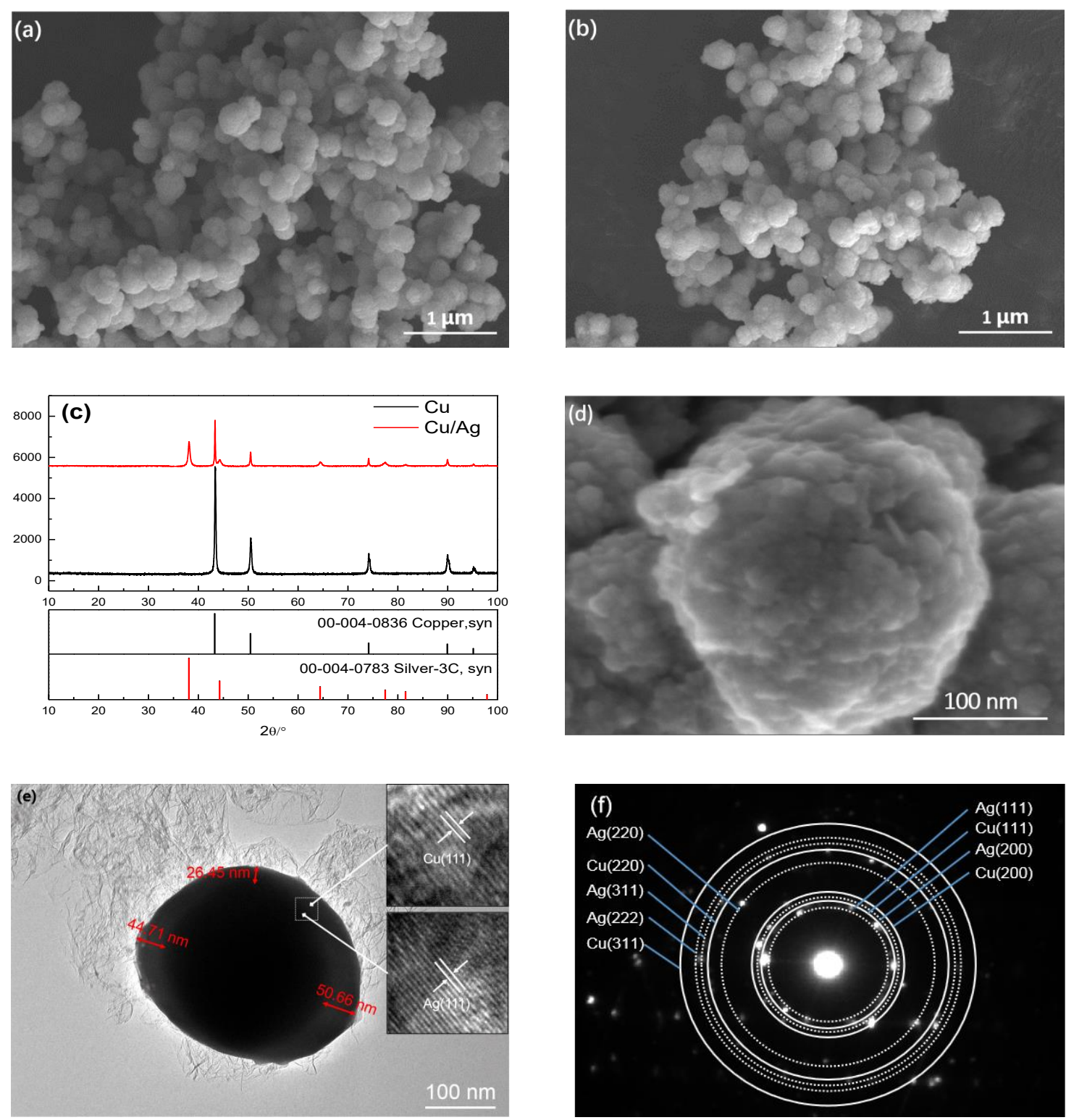

Figure 1. Cont. 


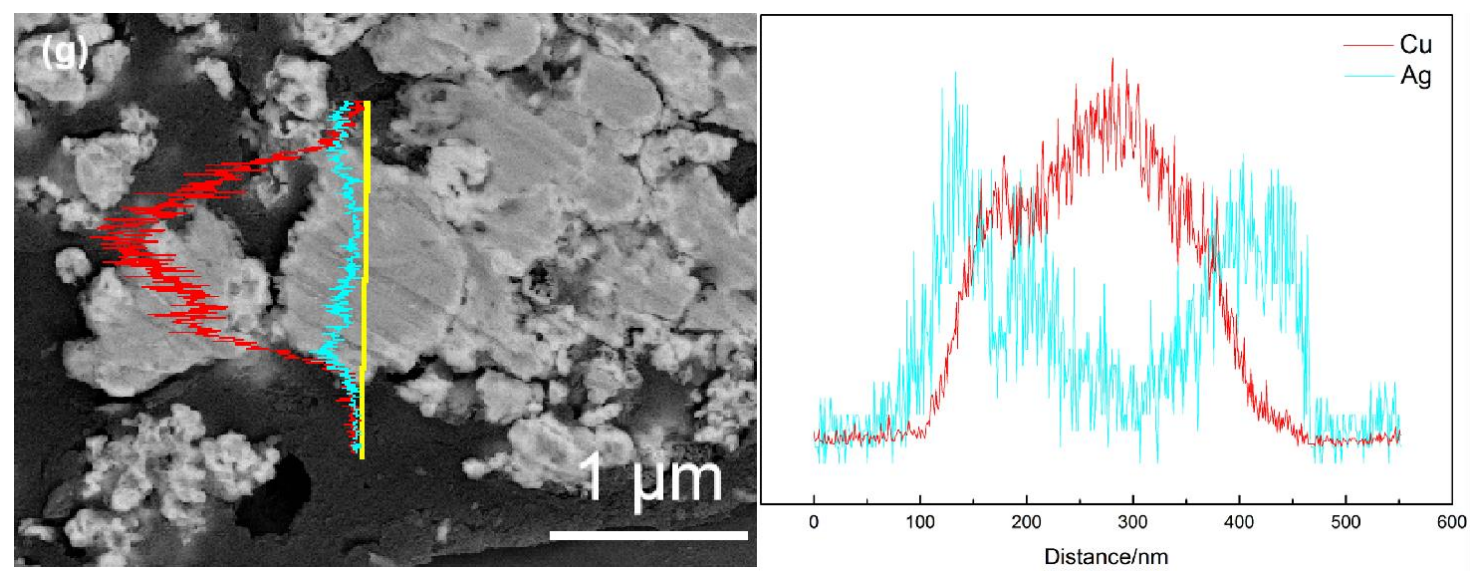

(h)
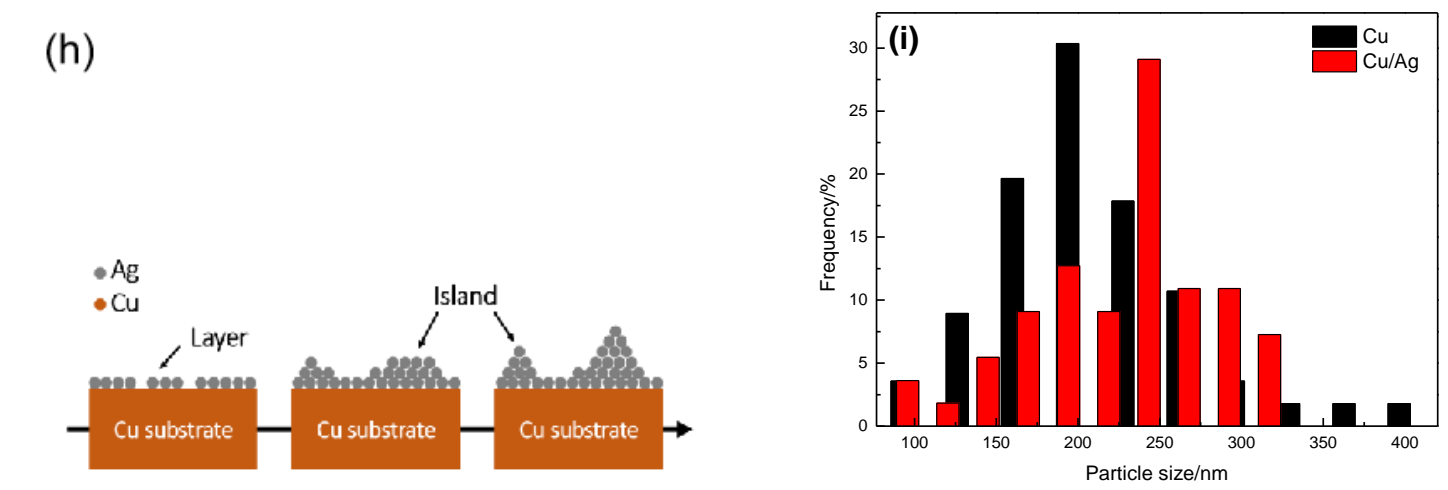

Figure 1. (a) Scanning electron microscope (SEM) image of $\mathrm{Cu}$ particles; (b) an SEM image of $\mathrm{Cu} / \mathrm{Ag}$ core-shell composite; (c) X-ray diffraction (XRD) patterns of $\mathrm{Cu}$ particles and $\mathrm{Cu} / \mathrm{Ag}$ core-shell composite; (d) a high magnification SEM image of $\mathrm{Cu} / \mathrm{Ag}$ core-shell composite; (e) a transmission electron microscope (TEM) image of $\mathrm{Cu} / \mathrm{Ag}$ core-shell composite; (f) SAED patterns of $\mathrm{Cu} / \mathrm{Ag}$ core-shell composite; (g) an SEM cross-section image of $\mathrm{Cu} / \mathrm{Ag}$ core-shell composite; (h) a schematic diagram of the growth mode of the silver coating; (i) the particle size distribution of $\mathrm{Cu}$ and $\mathrm{Cu} / \mathrm{Ag}$ core-shell composite.

For low-dimensional $\mathrm{Cu} / \mathrm{Ag}$ core-shell structures, there are three heteroepitaxial growth modes of Ag coating, namely the Frank-Van der Merwe (FM) mode, the Volmer-Weber (VW) mode, and Stranski-Krastanow (SK) mode. In this work, Ag grows in a three-dimensional space, so whether the growth of Ag proceeds in the SK mode remains to be verified. The schematic diagram of SK growth mode is shown in Figure 1h. The growth mode of the epitaxial layer depends on the free energy of the system, and also reflects the competitive balance between strain energy and surface energy and interface energy. Therefore, the experimental conclusion can be verified by calculating the energy relationship of the interface system by the first principles [18].

\subsection{Geometric Optimization}

Based on the speculation obtained above, a $\mathrm{Cu} / \mathrm{Ag}$ interface model was established to calculate interface properties and verify the growth mode. As the modeling method of the $\mathrm{Cu} / \mathrm{Ag}$ core-shell system is seldom reported in the literature, in order to ensure that the simulation calculation is closer to the actual situation and the calculation result can be applied to a larger scale, a vacuum slab model is used. This does not change the periodicity of $\mathrm{Cu}$ and $\mathrm{Ag}$, and does not limit the physical size of the material, making the calculation more convincing and universal.

For the choice of atomic layers, it is necessary to satisfy that the atoms in the depth of the surface have bulk atomic characteristics. On the other hand, with the increase in atomic layers, the computational time will increase. Therefore, the number of atomic layers in each surface model 
is taken as 5 layers. Since the spherical particles grow in all directions of space, one-dimensional, two-dimensional, and three-dimensional directions are selected separately when the model is built. Establishing representative (111), (110), and (100) surface models in the [111], [110], and [100] directions can be closer to the actual situation. The surface energy is calculated after geometric optimization, which is shown in Table 1. In density functional theory, surface energy can be calculated from the following expression [19]:

$$
E_{\text {sur }}=\frac{E_{\text {slab }}-n E_{\text {bulk }}}{2 A}
$$

where $E_{\text {slab }}$ is the total energy of surface slab obtained using density functional theory. $\mathrm{n}$ is the number of atoms in the surface slab. $E_{\text {bulk }}$ is the bulk energy per atom. $A$ is the surface area. For a slab, we have two surfaces and they are of the same type, which is reflected by the number 2 in the denominator.

Table 1. Surface energy after geometric optimization.

\begin{tabular}{cccccccc}
\hline Species & Surface & $\boldsymbol{E}_{\text {slab }}(\mathrm{eV})$ & $\boldsymbol{E}_{\text {bulk }}(\mathrm{eV})$ & $\boldsymbol{n}$ & $\mathbf{A}\left(\AA^{\mathbf{2}}\right)$ & $\boldsymbol{E}_{\text {sur }}(\mathrm{eV})$ & $\boldsymbol{E}_{\text {sur }}\left(\mathbf{J} / \mathbf{m}^{\mathbf{2}}\right)$ \\
\hline \multirow{3}{*}{$\mathrm{Cu}$} & $(111)$ & -7381.8278 & -1472.4135 & 5 & 5.6585 & -1.7461 & -27.9370 \\
& $(110)$ & $-14,763.6947$ & -1472.4135 & 10 & 9.2406 & -2.1405 & -34.2485 \\
& $(100)$ & $-14,764.3335$ & -1472.4135 & 10 & 6.5341 & -3.0761 & -49.2168 \\
$\mathrm{Ag}$ & $(111)$ & -5136.5884 & -1024.6651 & 5 & 7.2298 & -0.9172 & -14.6758 \\
& $(110)$ & $-10,273.4678$ & -1024.6651 & 10 & 11.8066 & -1.1357 & -18.1707 \\
& $(100)$ & $-10,273.9832$ & -1024.6651 & 10 & 8.3485 & -1.6370 & -26.1912 \\
\hline
\end{tabular}

Figure 2 displays the interface models and evaluating the relatively stable interface model by calculating the interface binding energy, the density of states and population. For each set of images, the model below is the geometric optimization result of the above. For $\mathrm{Cu}(111), \mathrm{Cu}(110)$, and $\mathrm{Cu}(100)$, their surface energy varies considerably, which proves that the active sites on the surface of $\mathrm{Cu}$ particles are unevenly distributed. This difference in activity influences the rate of reaction, resulting in vacancies on the surface.

(a)

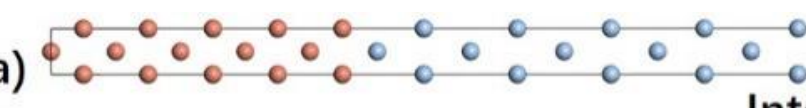

\section{Interface}

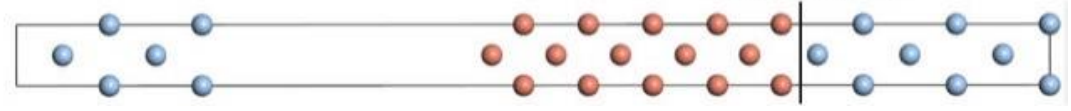

(b)
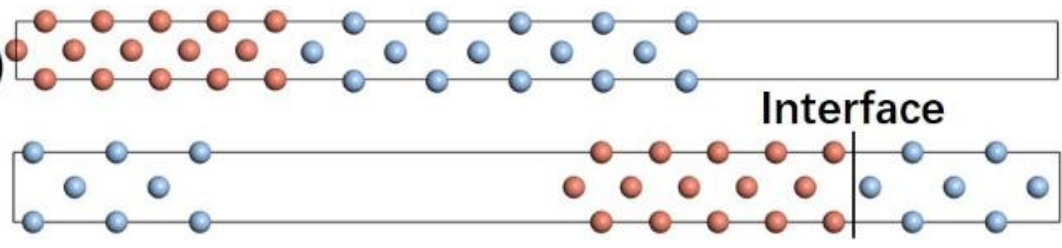

(c)

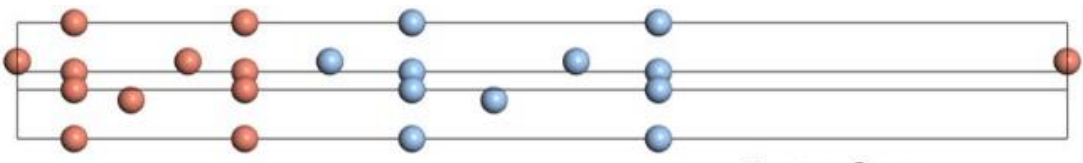

Interface

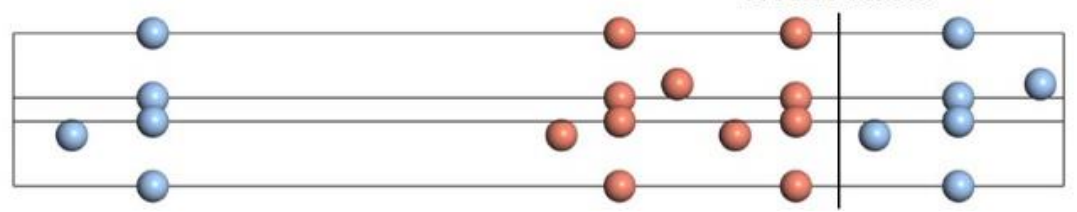

Figure 2. The structures of the $\mathrm{Cu} / \mathrm{Ag}$ interface. (a) $\mathrm{Ag}(100) / \mathrm{Cu}(100) ;(\mathbf{b}) \mathrm{Ag}(110) / \mathrm{Cu}(110) ;(\mathbf{c}) \mathrm{Ag}(111) / \mathrm{Cu}(111)$. 
The stability and combination of the interface are usually expressed by the interface energy, as given in Equation (7) [20].

$$
\gamma_{\text {int }}=\frac{\left(E_{A g}+E_{C u}-E_{C u / A g}\right)}{A}
$$

where $E_{A g}$ and $E_{C u}$ denote the total energies of the $\mathrm{Ag}(\mathrm{hkl})$ slab and the $\mathrm{Cu}(\mathrm{hkl})$ slab with five atomic layers, respectively, $E_{\mathrm{Cu} / \mathrm{Ag}}$ is the total energies of $\mathrm{Cu} / \mathrm{Ag}$ slab, and $\mathrm{A}$ is the interface area.

The interface energy is shown in Table 2. In the absence of special instructions, the comparison between energy does not take into account the sign. The order of the absolute values of interface energy indicates that the $\mathrm{Ag}(100) / \mathrm{Cu}(100)$ interface is the most stable structure.

Table 2. The work of adhesion and interface energy at the $\mathrm{Ag} / \mathrm{Cu}$ interface.

\begin{tabular}{cccc}
\hline Interface & $\gamma_{\text {int }} / \mathbf{e V} \cdot \AA^{\mathbf{2}}$ & $\mathbf{A} / \AA^{\mathbf{2}}$ & Bond Length/̊ \\
\hline $\operatorname{Ag}(111) / \mathrm{Cu}(111)$ & 0.2452 & 6.9218 & 2.9372 \\
$\mathrm{Ag}(110) / \mathrm{Cu}(110)$ & 0.4996 & 9.1618 & 2.6709 \\
$\mathrm{Ag}(100) / \mathrm{Cu}(100)$ & 0.5425 & 8.1644 & 2.6459 \\
\hline
\end{tabular}

The total free energy of the model determines the growth pattern of the Ag coating, usually represented by Equation (8) [21]. However, the correspondence between the growth mode and the free energy of the model is not clear, and the calculation of strain energy is difficult. Therefore, the growth mode of the coating is determined by calculating the energy relationship between the substrate, the coating, and the interface.

$$
F=E_{\text {strain }}+\sigma+\gamma_{\text {int }}
$$

where $F$ denotes the total free energy of the model, $E_{\text {strain }}$ is the strain energy of the model, $\sigma$ is the surface energy of the model, and $\gamma_{\text {int }}$ is the interface energy of the model.

According to the data in Table 2, the energy relationship between the substrate, the coating, and the interface can be obtained, which is presented in Table 3 . The surface energy of the substrate $\left(\sigma_{\mathrm{Cu}}\right)$ is greater than the sum of the surface energy of the coating $\left(\sigma_{\mathrm{Ag}}\right)$ and the interface energy $\left(\gamma_{\text {int }}\right)$. It is found that the interface energy is small, and the epitaxial material atoms are distributed on the substrate, and a thin strain layer is formed on the surface in the pre-stage. As the epitaxial growth progresses, the elastic strain in the epitaxial layer increases as the layer thickness increases. When the thickness of the epitaxial layer is raised to a certain value, the strain energy accumulated in the strained layer is released by redistributing the atoms reaching the surface to form a three-dimensional island. It is pointed out that although the formation of the island increases the surface energy, but reduces the total energy of the epitaxial layer. The surface energy of slab models is shown in Table 4 and the positive and negative of energy is not considered. It is noted that the surface energy of the slab models is indeed reduced, as in the conclusions of the literature [22].

Table 3. The relationship between two surfaces and interface.

\begin{tabular}{cccc}
\hline Interface & $\boldsymbol{\sigma}_{\mathbf{C u}} / \mathbf{e V} \cdot \AA^{2}$ & Relationship & $\boldsymbol{\sigma}_{\mathbf{A g}} / \mathbf{e V} \cdot \AA^{2}$ \\
\hline $\operatorname{Ag}(111) / \mathrm{Cu}(111)$ & 1.7461 & $>$ & 0.9172 \\
$\operatorname{Ag}(110) / \mathrm{Cu}(110)$ & 2.1405 & $>$ & 1.1357 \\
$\operatorname{Ag}(100) / \mathrm{Cu}(100)$ & 3.0761 & $>$ & 1.6370 \\
\hline
\end{tabular}


Table 4. The surface properties of slab models.

\begin{tabular}{ccccc}
\hline & Surface & $n_{\mathbf{C u}} / \boldsymbol{n}_{\mathbf{A g}}$ & $\mathbf{A}\left(\AA^{\mathbf{2}}\right)$ & $\boldsymbol{E}_{\text {sur }}(\mathbf{e V})$ \\
\hline \multirow{3}{*}{ Cu slab } & $(111)$ & $5 / 0$ & 5.6585 & 1.7461 \\
& $(110)$ & $10 / 0$ & 9.2406 & 2.1405 \\
& $(100)$ & $10 / 0$ & 6.5341 & 3.0761 \\
$\mathrm{Cu} / \mathrm{Ag}$ slab & $\mathrm{Ag}(111) / \mathrm{Cu}(111)$ & $5 / 5$ & 7.7039 & 0.0006 \\
& $\mathrm{Ag}(110) / \mathrm{Cu}(110)$ & $10 / 10$ & 9.1618 & 0.0880 \\
& $\mathrm{Ag}(100) / \mathrm{Cu}(100)$ & $10 / 10$ & 8.1644 & 1.5601 \\
\hline
\end{tabular}

\subsection{Population Analysis of Interface}

Mulliken population refers to the distribution of electrons in each atomic orbit. By analyzing the atomic charge population, the bonding between atoms at the interface and the amount of charge transfer can be known. Table 5 shows the atomic charge population of the interface models. According to the data in the table, the $\mathrm{Cu}$ and $\mathrm{Ag}$ atoms in each model are positively and negatively charged, and the number of electrons obtained by the $\mathrm{Cu}$ atoms is equal to the number of electrons lost by the $\mathrm{Ag}$ atoms. It is indicated that $\mathrm{Cu}$ atoms transfer electrons to $\mathrm{Ag}$ atoms, which form ionic bonds (underlined data). However, the data that is not marked differs greatly, so it can be concluded that there are other bonds or forces in the interface. According to the Mulliken bond population, the values of each group are less than 1, indicating that the Ag-Cu bond contains both covalent bonds and ionic bonds. For the $\mathrm{Ag}(111) / \mathrm{Cu}(111)$ interface, the Mulliken bond population is close to 0 , showing a strong ionic bond property, and it also shows that the interface stability gradually decreases as the crystal face index increases. In other words, with the epitaxial growth of the Ag layer, the stability is gradually reduced, eventually causing the morphology to be unstable, resulting in a rough surface of the material.

Table 5. The atomic charge and Mulliken bond population of $\mathrm{Ag}(\mathrm{hkl}) / \mathrm{Cu}(\mathrm{hkl})$ interfaces.

\begin{tabular}{ccccccc}
\hline \multirow{2}{*}{ Species } & \multicolumn{2}{c}{$\mathbf{A g ( 1 1 1 ) / C u ( 1 1 1 )}$} & \multicolumn{2}{c}{$\mathbf{A g ( 1 1 0 ) / C u ( 1 1 0 )}$} & \multicolumn{2}{c}{$\operatorname{Ag(100)/Cu(100)}$} \\
& Population & Charge(e) & Population & Charge(e) & Population & Charge(e) \\
\hline $\mathrm{Cu}$ & 11.00 & $0.04 /-0.08$ & 11.01 & $0.03 /-0.11$ & 11.01 & $0.02 /-0.09$ \\
$\mathrm{Ag}$ & 10.99 & $0.04 /-0.05$ & 10.99 & $0.02 /-0.03$ & 10.99 & $0.03 /-0.02$ \\
$\mathrm{Cu}-\mathrm{Cu}$ & $0.61 /-0.64$ & - & $0.54 /-0.20$ & - & 0.72 & - \\
$\mathrm{Ag}-\mathrm{Ag}$ & -0.43 & - & $0.62 /-0.09$ & - & $0.47 /-0.19$ & - \\
$\mathrm{Ag}-\mathrm{Cu}$ & 0.32 & - & 0.68 & - & 0.62 & - \\
\hline
\end{tabular}

\subsection{Electronic Structure Analysis of Interface}

To investigate the differences in bonding ability, the density of states is calculated where the Fermi level $E_{\mathrm{F}}$ is set at the position of energy $E=0 \mathrm{eV}$, as shown in Figure 3. The $E_{\mathrm{F}}$ of DOS for each model is larger than 0 , indicating that both the $\mathrm{Ag}$ and $\mathrm{Cu}$ slab in the interface system maintain the metallic characteristic. The DOS of the Ag atoms is mainly contributed by the valence electrons of $\mathrm{Ag} 4 \mathrm{~d}$ and a small amount of $\mathrm{Ag} 4 \mathrm{p}, \mathrm{Ag} 5 \mathrm{~s}$ orbitals, and the DOS of the $\mathrm{Cu}$ atoms is mainly contributed by the valence electrons of $\mathrm{Cu} 3 \mathrm{~d}$ and a small amount of $\mathrm{Cu} 3 \mathrm{p}, \mathrm{Cu} 4 \mathrm{~s}$ orbitals. Except for peak and peak shapes, the density of states of different models is comparable, and the $\mathrm{d}$ orbital of the $\mathrm{Cu}$ atom overlaps with the $\mathrm{d}$ orbital of the $\mathrm{Ag}$ atom, resulting in hybridization and a strong interaction. Figure $3 \mathrm{~d}$ shows the density of states of $\mathrm{Cu}$ and $\mathrm{Ag}$ atoms in the $\mathrm{Ag}(100) / \mathrm{Cu}(100)$ model, and the density of states of the $\mathrm{Cu}$ and $\mathrm{Ag}$ atoms in other interfaces is not given because the stability of $\mathrm{Ag}(100) / \mathrm{Cu}(100)$ is the highest and the peak is more obvious. It is exhibited that the $\mathrm{p}$ orbital of the $\mathrm{Cu}$ atom also overlaps with the $\mathrm{d}$ orbital of the Ag atom but it is not obvious. Moreover, the charge density distribution and the difference charge density distribution of the interface can show the electron transfer and electron density of interfaces more intuitively. The unit of the values in Figure 4 is all electrons/ $\AA^{3}$. There is a phenomenon of charge accumulation and electron transfer between $\mathrm{Cu}$ and $\mathrm{Ag}$, indicating that they are connected by ionic bonds with covalent properties. For the $\mathrm{Ag}(111) / \mathrm{Cu}(111)$ model, although 
$\mathrm{Cu}$ and $\mathrm{Ag}$ in the vicinity of the interface have common electrons, the density is extremely low, and mainly free electrons are present. Therefore, there is a strong metal bond between $\mathrm{Cu}$ and $\mathrm{Ag}$. For the $\mathrm{Ag}(110) / \mathrm{Cu}(110)$ and $\mathrm{Ag}(100) / \mathrm{Cu}(100)$ models, the latter exhibits more common electrons and strong covalent bonds. However, the mismatch of the $\mathrm{Cu} / \mathrm{Ag}$ interface is large (more than $15 \%$ ), so there are non-bonding forces and strain at the interface, which requires further calculations.
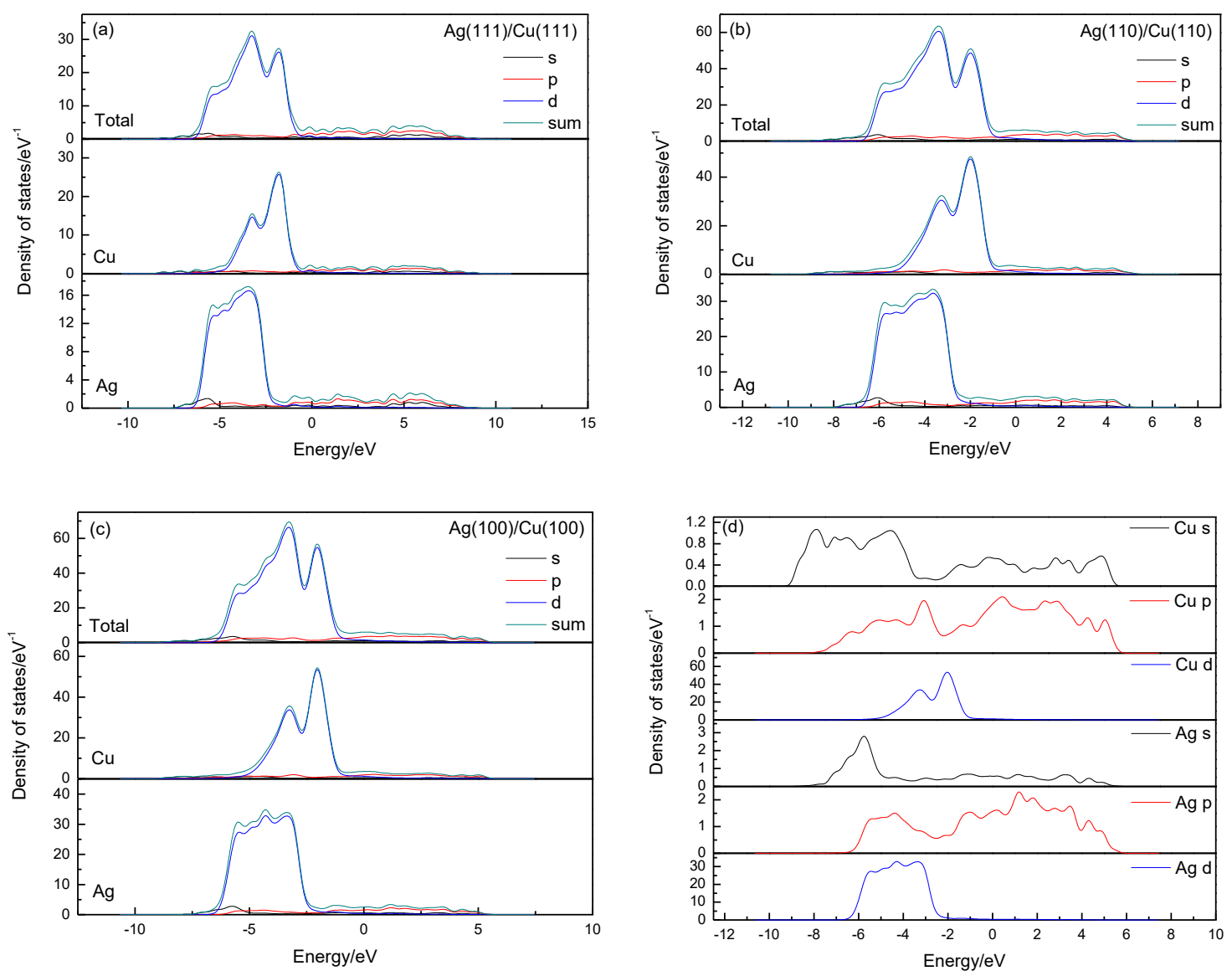

Figure 3. Density of states of the interface of $\mathrm{Cu} / \mathrm{Ag}$ composite. (a) PDOS of $\mathrm{Ag}(111) / \mathrm{Cu}(111)$; (b) PDOS of $\mathrm{Ag}(110) / \mathrm{Cu}(110)$; (c) PDOS of $\mathrm{Ag}(100) / \mathrm{Cu}(100)$; (d) PDOS of $\mathrm{Cu}$ and $\mathrm{Ag}$ atoms in $\mathrm{Ag}(100) / \mathrm{Cu}(100)$. 

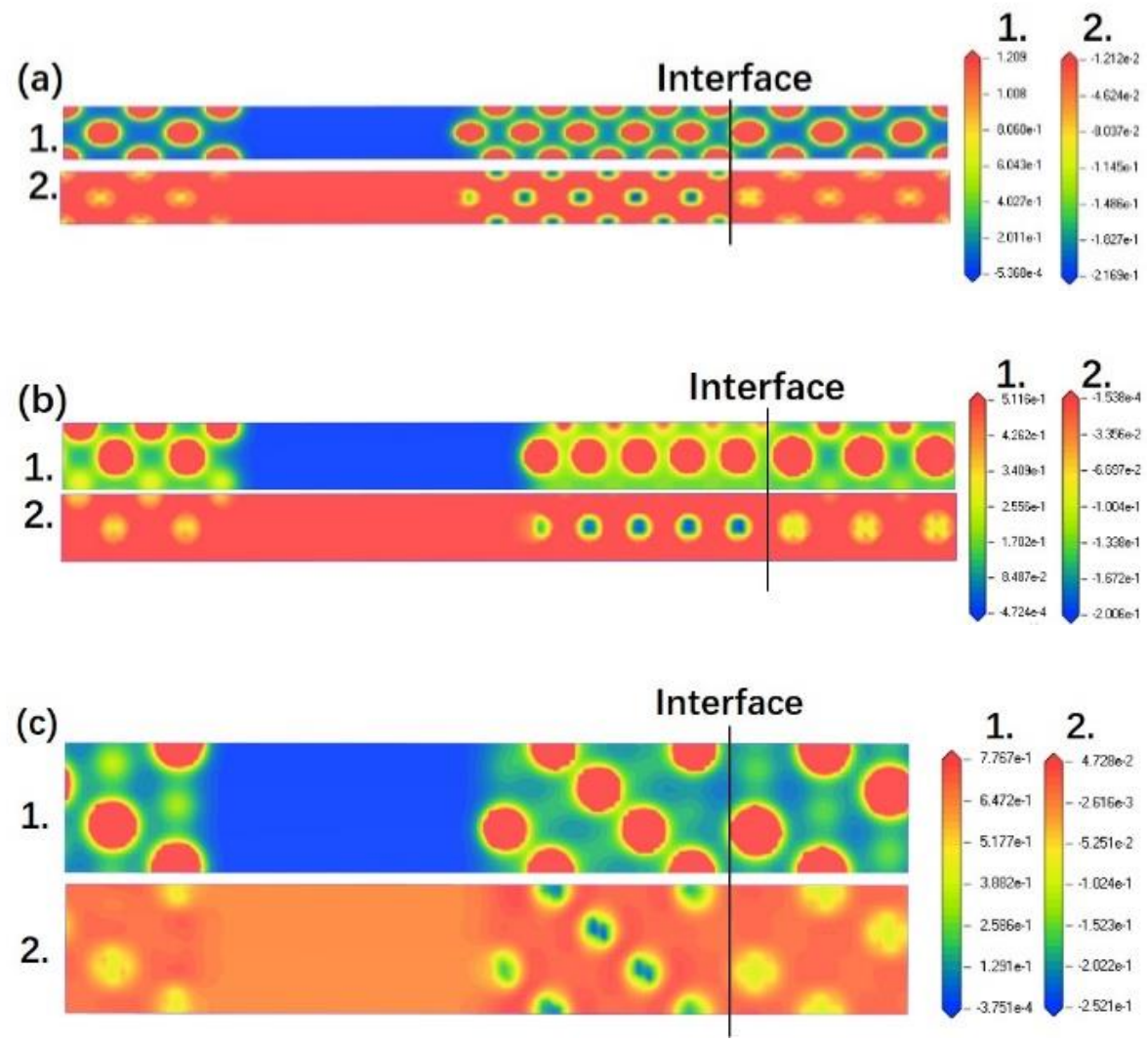

Figure 4. The charge density distribution and the difference charge density distribution of the interface. (a) $\mathrm{Ag}(100) / \mathrm{Cu}(100)$; (b) $\mathrm{Ag}(110) / \mathrm{Cu}(110)$; (c) $\mathrm{Ag}(111) / \mathrm{Cu}(111)$.

\subsection{Force Analysis of Interface}

To further describe the forces between $\mathrm{Cu}$ and $\mathrm{Ag}$, the radial distribution function is calculated, as shown in Figure 5. In all models, there is a maximum in the range of $r<2.6 \AA$, indicating that the bond is the main force that constitutes the interface. However, for the $\mathrm{Ag}(100) / \mathrm{Cu}(100)$, there also peaks with high peaks in the range of 2.6-3.1 $\AA$, indicating that there are strong hydrogen bonds in the interface. Besides, there are also peaks in the range of $r>3.1 \AA$, exhibiting Van der Waals force [23].
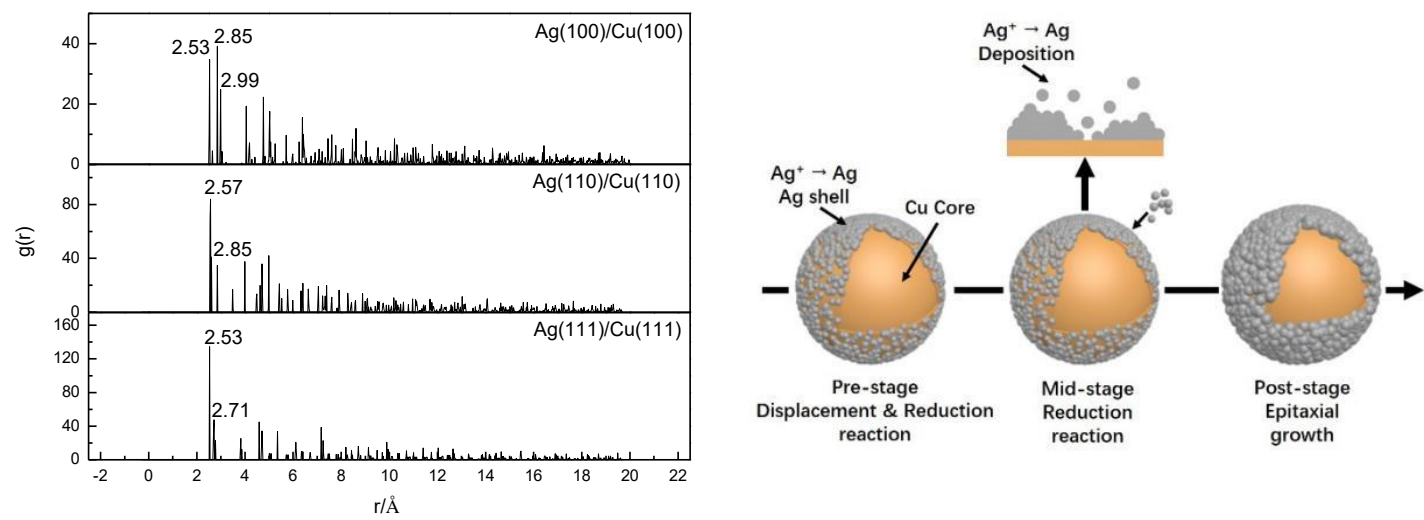

Figure 5. The radial distribution function of interface and the three-dimensional schematic diagram.

According to the above conclusion, the growth mode of the Ag coating can be inferred, and the three-dimensional schematic diagram is also as shown in Figure 5. The growth of the Ag coating is mainly composed of three stages. 
Pre-stage: The displacement reaction and the direct reduction reaction occur simultaneously in the solution, but since the surface energy of each surface of $\mathrm{Cu}$ differs, the reactivity of each surface also differs, resulting in the formation of vacancies and a thin layer of $\mathrm{Ag}$ on the $\mathrm{Cu}$ surface.

Min-stage: As the direct reaction of Ag continues, the $\mathrm{Cu}$ surface is covered by Ag and the vacancies disappear. When the coating reaches a certain thickness, the strain energy of each surface is released outward, resulting in irregular protrusions on the surface of the composite.

Post-stage: As the reaction progresses, the $\mathrm{Ag}^{+}$ion concentration in the solution gradually decreases, the reaction reaches equilibrium, and the growth of the Ag coating stops.

Regarding the core of a regular geometry, especially two elements (such as $\mathrm{Pb}$ and $\mathrm{Pt}$ ) that differ by one period from the periodic table, the conclusions reached are similar. The growth of the shell is divided into two stages, that is, the shell grows epitaxially, and then the island grows. The difference is that the simulation calculation and characterization of core-shell particles with a spherical structure are more complex, and are easily affected by external factors during the synthesis [24]. In this paper, calculations and characterizations confirm each other, indicating that the method is credible.

\section{Conclusions}

$\mathrm{Cu} / \mathrm{Ag}$ core-shell composite can be synthesized by the replacement-reduction method. According to the characterization results, the depositing of the Ag coating increases the particle size, and there are irregular protrusions on the surface of the particles. To investigate the growth mode of the Ag coating, the first-principles calculation is used to analyze the $\mathrm{Ag} / \mathrm{Cu}$ interface structure to infer the growth mode of the Ag coating. It is found that the growth mechanism of the Ag coating belongs to the Stranski-Krastanow (SK) mode and is divided into three steps. Since the Ag/Cu interface contains bonds, hydrogen bonds, and van der Waals forces, the bond strength between the coating and the substrate is weak, but this result is not obvious in the early growth stage. As the thickness of the coating increases, the particle must reduce the surface energy to reach equilibrium. Therefore, the strain energy generated by the lattice mismatch at the interface must be released, eventually leading to irregular protrusions on the surface of the particle. The core-shell composite synthesized according to the SK mode can greatly reduce defects due to lattice mismatch. At the same time, this research method is also applicable to more complex core-shell composites, and also provides theoretical support for the preparation and modification of core-shell composites.

Author Contributions: Conceptualization, X.W. and Y.W.; methodology, J.L. (Jinlin Lu); software, X.W.; validation, X.W., Z.N. and J.L. (Jidong Li); formal analysis, X.W. and Y.W.; funding acquisition, Y.W. All authors have read and agreed to the published version of the manuscript.

Funding: This research was funded by National Natural Science Foundation of China (51674141), University of Science and Technology Liaoning Graduate Education Reform and Technology Innovation and Entrepreneurship Project (LKDYC201901), University of Science And Technology Liaoning Talent Project Grants (601011507-14).

Conflicts of Interest: There are no conflicts of interest to declare.

\section{References}

1. Nagahama, C.; Zinchenko, A. Small DNA additives to polyelectrolyte multilayers promote formation of ultrafine gold nanoparticles with enhanced catalytic activity. Colloid Polym. Sci. 2019, 297,363-369. [CrossRef]

2. Zhu, B.; Li, K.; Feng, Y.; Zhang, S.; Wu, S.; Huang, W. Synthesis and catalytic performance of gold-loaded $\mathrm{TiO}_{2}$ nanofibers. Catal. Lett. 2007, 118, 55-58. [CrossRef]

3. Mei, Y.; Sharma, G.; Lu, Y.; Ballauff, M.; Drechsler, M.; Irrgang, T.; Kempe, R. High catalytic activity of platinum nanoparticles immobilized on spherical polyelectrolyte brushes. Langmuir 2005, 21, 12229-12234. [CrossRef] [PubMed]

4. Hillier, A.C.; Grasa, G.A.; Viciu, M.S.; Lee, H.M.; Yang, C.1.; Nolan, S.P. Catalytic cross-coupling reactions mediated by palladium/nucleophilic carbene systems. J. Organomet. Chem. 2002, 653, 69-82. [CrossRef]

5. Xie, W.; West, D.J.; Sun, Y.; Zhang, S. Role of nano in catalysis: Palladium catalyzed hydrogen desorption from nanosized magnesium hydride. Nano Energy 2013, 2, 742-748. [CrossRef] 
6. Choudary, B.M.; Madhi, S.; Chowdari, N.S.; Kantam, M.L.; Sreedhar, B. Layered double hydroxide supported nanopalladium catalyst for Heck-, Suzuki-, Sonogashira-, and Stille-type coupling reactions of chloroarenes. J. Am. Chem. Soc. 2002, 124, 14127-14136. [CrossRef]

7. Hickman, A.J.; Sanford, M.S. High-valent organometallic copper and palladium in catalysis. Nature 2012, 484, 177-185. [CrossRef]

8. Tegoua, A.; Papadimitrioua, S.; Pavlidoub, E.; Kokkinidisa, G.; Sotiropoulosa, S. Oxygen reduction at platinum- and gold-coated copper deposits on glassy carbon substrates. J. Electroanal. Chem. 2007, 608, 66-77. [CrossRef]

9. Peng, Y.; Yang, C.; Chen, K.; Popuri, S.R.; Lee, C. Study on synthesis of ultrafine Cu-Ag core-shell powders with high electrical conductivity. Appl. Surf. Sci. 2012, 263, 38-44. [CrossRef]

10. Meng, Z.H.; Xie, K.N.; Liao, L.; Li, Y.J. Preparation and characterization of Ag-Cu coated powder. J. Funct. Materials 2013, 11, 1656-1662.

11. Nian, P.; Li, Y.; Zhang, X.; Cao, Y.; Liu, H.; Zhang, X. ZnO Nanorod-induced heteroepitaxial growth of SOD type Co-based zeolitic imidazolate framework membranes for $\mathrm{H}_{2}$, separation. ACS Appl. Mater. Inter. 2018, 10, 4151-4160. [CrossRef]

12. Shi, Z.; Li, H.; Yuan, Q. Van der waals heteroepitaxial growth of monolayer $\mathrm{Sb}$ in a puckered honeycomb structure. Adv. Mater. 2018, 31, 1806130. [CrossRef] [PubMed]

13. Weng, W.; Hsu, C.; Lee, J.; Fan, H.; Liao, C. Twin-mediated epitaxial growth of highly lattice-mismatched $\mathrm{Cu} /$ Ag core-shell nanowires. Nanoscale. 2018, 10, 9862-9866. [CrossRef] [PubMed]

14. Khoo, K.H.; Arantes, J.T.; Chelikowsky, J.R.; Dalpian, G.M. First-principles calculations of lattice-strained core-shell nanocrystals. Phys. Rev. B. 2011, 84, 075311. [CrossRef]

15. Kong, X.; Wang, J. Copper(II) adsorption on the kaolinite(001) surface: Insights from first-principles calculations and molecular dynamics simulations. Appl. Surf. Sci. 2016, 389, 316-323. [CrossRef]

16. Lee, T.K.; Chiang, C.S.; Lee, W.H. A study on $\mathrm{Cu}$ particles coated with nano-silver by a replacement reaction between silver nitrate and copper particles. J. Nanosci. Nanotechnol. 2017, 17, 4157-4161. [CrossRef]

17. Kim, J.J.; Lee, H.W.; Dabhade, V.V.; Kim, S.R.; Kwon, W.T.; Choi, D.J.; Kim, H.; Kim, Y. Electro magnetic interference shielding characteristic of silver coated copper powder. Met. Mater. Int. 2010, 16, 469-475. [CrossRef]

18. Ledentsov, N.N.; Shchukin, V.A.; Grundmann, M.; Kirstaedter, N.; Böhrer, J.; Schmidt, O.; Bimberg, D.; Ustinov, V.M.; Egorov, A.Y.; Zhukov, A.E.; et al. Direct formation of vertically coupled quantum dots in Stranski-Krastanow growth. Phys. Rev. B 1996, 54, 8743. [CrossRef]

19. Zhao, X.; Zhuo, Y.; Liu, S.; Zhou, Y.; Zhao, C.; Wang, C.; Yang, Q. Investigation on WC/TiC interface relationship in wear-resistant coating by first-principles. Surf. Coat. Technol. 2016, 305, 200-207. [CrossRef]

20. Yang, D.; Liu, H.; Liu, L.; Sarina, S.; Zheng, Z.; Zhu, H. Silver oxide nanocrystals anchored on titanate nanotubes and nanofibers: Promising candidates for entrapment of radioactive iodine anions. Nanoscale 2013, 5, 11011-11018. [CrossRef]

21. Antanobich, A.; Achtstein, A.; Matsukovich, A.; Prudnikau, A.; Bhaskar, P.; Gurin, V.; Molinari, M.; Artemyev, M. Strain-induced exciton transition energy shift in CdSe nanoplatelets: The impact of the organic ligand shell. Nanoscale 2017, 9, 18042-18053. [CrossRef] [PubMed]

22. Attard, G.A. A phenomenological theory of electrosorption. Electroanal. Chem. 2018, 819, 481-494. [CrossRef]

23. Kellerman, D.; Medvedeva, N.; Mukhina, N.; Semenova, A.; Baklanova, I.; Perelyaeva, L.; Gorshkov, V. Vanadium doping of LiMnPO4: Vibrational spectroscopy and first-principle studies. Chem. Phys. Lett. 2014, 591, 21-24. [CrossRef]

24. Xiong, Y.; Ma, Y.; Li, J.; Huang, J.; Yan, Y.; Zhang, H.; Wu, J.; Yang, D. Stran-induced Stranski-Krastanov growth of Pd@Pt core-shell hexapods and octapods as electrocatalysts for methanol oxidation. Nanoscale 2017, 9, 11077-11084. [CrossRef]

(C) 2020 by the authors. Licensee MDPI, Basel, Switzerland. This article is an open access article distributed under the terms and conditions of the Creative Commons Attribution (CC BY) license (http://creativecommons.org/licenses/by/4.0/). 